\title{
Análise de Ensaio ao Impacto em Corpo de Prova
}

\author{
Evandro Bertoldi ${ }^{1}$ \\ ${ }^{1}$ UNIJUÍ - Universidade Regional do Noroeste do Estado do Rio Grande do Sul \\ E-mail: evandrobertoldi@yahoo.com.br
}

\section{RESUMO}

A separação ou fragmentação de um corpo sólido em duas ou mais partes, pela ação de um esforço, é chamada fratura, e a capacidade de absorver energia até que essa fratura ocorra é a tenacidade do material. Considerando que o desempenho de alguns materiais é diretamente dependente da maneira como se aplica a carga, para situações de solicitações dinâmicas o ensaio de impacto é amplamente utilizado. Dentre suas vantagens, está o baixo custo e a relativa simplicidade na realização do ensaio. Realizou-se o ensaio de impacto Charpy em corpos de prova de aço SAE 1020, com entalhe em V, orientado transversalmente à direção de laminação. Esse ensaio foi realizado sob seis temperaturas $\left(25,10,-10,-30,-50\right.$ e $\left.-70^{\circ} \mathrm{C}\right)$. O ensaio e a confecção dos corpos de prova foram especificados pela norma ASTM A370, sendo as dimensões dos corpos de prova de 10x10x55mm. Verifica-se, através do ensaio de impacto, que a temperatura influencia na tenacidade do material, obtendo-se, para o corpo de prova ensaiado, uma estrutura frágil em baixas temperaturas e uma estrutura mais dúctil em temperatura ambiente. Dessa maneira, pode-se determinar o correto material a ser empregado em diversas temperaturas.

Palavras-chave: Ensaio ao Impacto Charpy, Energia Absorvida, Temperaturas de Ensaio, Tenacidade, Fratura.

\section{INTRODUÇÃO}

A determinação da tenacidade dos aços e outros materiais metálicos são realizados em processos de produção e controle de materiais para aplicações em diversos ramos industriais.

O interesse no estudo do comportamento dos materiais em função da temperatura iniciou-se na Segunda Guerra Mundial, quando se observou que no inverno alguns navios partiam-se ao meio, apresentando fratura frágil, tendo estes sido construídos com juntas soldadas de materiais com boa ductilidade, quando ensaiados em temperatura ambiente, Garcia, Spim e Santos [1].

Diante desse contexto, torna-se então uma das principais preocupações dos pesquisadores, e também dos engenheiros de aplicação dos materiais, prever em quais condições provavelmente uma fratura frágil ocorrerá, já que este é um tipo de colapso que ocorre abruptamente, não sendo possível esperar que se inicie para que então alguma providência seja tomada. 
O episódio dos navios de classe Liberty na $2^{\text {a }}$ Guerra Mundial, quando navios atracadados apresentavam fratura frágil, sem razão aparente e que surgiam de maneira totalmente inesperada, trouxe à tona a necessidade de determinar uma temperatura limite, abaixo da qual o comportamento à fratura do material se altera de dúctil para frágil, de maneira a prever e evitar ocorrências de fratura frágil catastrófica. A essa temperatura se deu o nome de temperatura de transição dúctil-frágil (TTDF) dos materiais, Hertzberg [2]. Atualmente, podese utilizar a afirmação de Horath [3] para auxiliar nesta definição. Este autor diz que há quatro considerações principais que devem ser feitas no momento de selecionar o tipo de ensaio a realizar, que são: o propósito do teste, a precisão desejada para o teste, qual equipamento disponível é mais simples, e ainda qual é o mais econômico. Além disso, é importante considerar as propriedades do material, lembrando-se das condições de uso às quais este material será submetido para então definir o teste mais apropriado a realizar.

Segundo Sumpter e Kent [4], a fratura dos navios Liberty no período de 1943 a 1953 contribuiu para o desenvolvimento de teorias modernas sobre mecânica de fratura. As incidências de fratura frágil observada nos navios nos anos 40, reduziram de 1 em 10 anos para uma incidência atual em torno de 1 em 104 anos de uso dos navios.

O ensaio mais simples e barato para a determinação dessa importante propriedade dos materiais é o ensaio de impacto Charpy, cujo princípio é a medida da energia de impacto absorvida por um corpo de prova prismático entalhado, bi-apoiado, sujeito a um golpe de um martelo pendular.

$\mathrm{Na}$ época da Segunda Guerra, entretanto, muito pouco sobre o assunto havia sido documentado, e dentre os ensaios disponíveis, o ensaio de impacto Charpy foi então considerado o ensaio que mais se adequava às necessidades para o estudo deste assunto, e permanece até hoje com ampla utilização para este fim.

O ensaio de impacto, também vem sendo pesquisado há muitos anos para o desenvolvimento de novos métodos e técnicas para determinar a tenacidade à fratura dinâmica, por exemplo, Ireland [5].

Para alguns pesquisadores como Burdekin e Folch [6], a TTDF é definida como a faixa de temperatura sobre a qual a mudança nos níveis de energia de baixo para alto ocorre. Porém, como na prática geralmente não ocorre uma variação brusca de energia, mas ocorre uma zona de transição, torna-se difícil determinar com precisão a TTDF. Assim, realiza-se uma série de ensaios a diferentes temperaturas, o que permite a determinação da TTDF, no qual é um parâmetro importante na seleção de um material do ponto de vista de tenacidade ou de tendência para a ocorrência de fratura frágil.

Para Benzerga, Desandre, Tvergaard e Needleman [7] a TTDF para um corpo de prova padrão ensaiado numa máquina numa velocidade de $5 \mathrm{~m} / \mathrm{s}$ é definida como a média entre a mais baixa temperatura para a qual o modo de fratura é puramente frágil e a mais alta temperatura para a qual o modo de fratura é dúctil.

Geralmente os ensaios de impacto mais amplamente utilizados apresentam-se da seguinte forma: Charpy e Izod. Para ambos os casos, o corpo de prova devidamente padronizado, tem o formato de uma barra com seção transversal quadrada, na qual é usinado um entalhe tipo $\mathrm{V}$. O diferencial entre os dois está na posição do entalhe na barra e a forma como são fixados 
para a aplicação da carga efetuada através de um martelo pendular que é liberado a partir de uma determinada altura que em contato instantâneo causará o rompimento da peça. De acordo com Souza [8], o entalhe produz um estado triplo de tensões, suficiente para provocar a ruptura de caráter frágil, mas que infelizmente não é possível medir satisfatoriamente os componentes das tensões existentes por diversos fatores como o tipo de metal usado ou conforme a estrutura interna que este mesmo material apresenta como característica.

O ensaio de impacto Charpy pode ser também efetuado realizando-se outros tipos de entalhes no corpo de prova além do entalhe em $\mathrm{V}$, ou tipo $\mathrm{A}$, que são: tipo $\mathrm{B}$, no qual possui uma forma de uma fechadura e o tipo $\mathrm{C}$, com a forma de $\mathrm{U}$ invertido. Este tipo de ensaio de impacto mostra versatilidade, e é o mais requisitado pelo posicionamento do corpo de prova na máquina, principalmente, quando se trata na determinação das transformações ocasionadas pela temperatura.

Em relação ao avanço do ensaio ao impacto, atualmente máquinas de impacto Charpy instrumentada são empregadas para avaliar a tenacidade de vários materiais, Kobayashi, Kim e Morita [9], Srivatsan, Lam e Krause [10], Zappini, Kammann e Wachter [11].

O ensaio de impacto Charpy apresenta vantagens como: uso de corpos de prova reduzidos; facilidade de execução; alta taxa de deformação; correlação com outros ensaios de fratura e economia, Kobayashi, Kim e Morita [9].

Diante deste contexto, têm-se como objetivo, demonstrar e conhecer o ensaio de impacto Charpy a partir de ensaios práticos em corpos de prova de acordo com os processos definidos em normas utilizando a máquina de ensaio de impacto. Além disso, pretende-se verificar o comportamento do material durante o ensaio prático em diferentes temperaturas, a fim de verificar a absorção de energia, identificando se o material apresenta fratura frágil ou dúctil.

Corpos de prova de aço SAE 1020, com entalhe em V, orientado transversalmente à direção de laminação, foram confeccionados para o ensaio de impacto Charpy conforme a norma ASTM A 370 [12], tendo como dimensões dos corpos de prova de 10x10x55mm. Diferentes temperaturas de ensaio foram utilizadas, visando abranger desde as temperaturas para as quais se espera que o material de interesse apresente fratura $100 \%$ frágil até as temperaturas para as quais ocorre fratura $100 \%$ dúctil.

\section{MATERIAIS E MÉTODOS}

A classificação do ensaio de Impacto tipo Charpy é considerada como dinâmico, e por si só tal designação já abriga a mão de obra e os cuidados necessários para validarem este ensaio, que é um dos mais utilizados por aqueles que trabalham com materiais metálicos. A prática padrão em estudo pode obter valores que representam a tenacidade ao impacto do material, como a energia absorvida, o percentual de cisalhamento da fratura, a expansão lateral em frente ao entalhe ou a combinação dos mesmos de acordo com as normas.

Deve-se ter todo o cuidado com a preparação dos corpos de prova para a realização do ensaio, pois os mesmos podem comprometer os resultados. A desconsideração dos valores mais extremos, ou seja, o menor e o maior valor são aconselháveis justamente para minimizar os efeitos de parâmetros não corrigidos antes da execução deste tipo de ensaio. A temperatura é um dos parâmetros mais importantes para ser aferida durante a realização do ensaio como sugerem as normas utilizadas. 


\subsection{Ensaio de Impacto e a sua Utilização para Estudo da Tenacidade dos Materiais}

De acordo com Meyers e Chawla [13], a separação ou fragmentação de um corpo sólido em duas ou mais partes, pela ação de um esforço, é chamada fratura, e a capacidade de absorver energia até que essa fratura ocorra é a tenacidade do material que constitui este corpo sólido. Em termos de solicitações estáticas, a tenacidade de um material pode ser avaliada por meio de um gráfico de tensão em função da deformação obtido por ensaio de tração, correspondendo à área abaixo da curva até seu ponto de fratura, conforme mostrado na Figura 1.

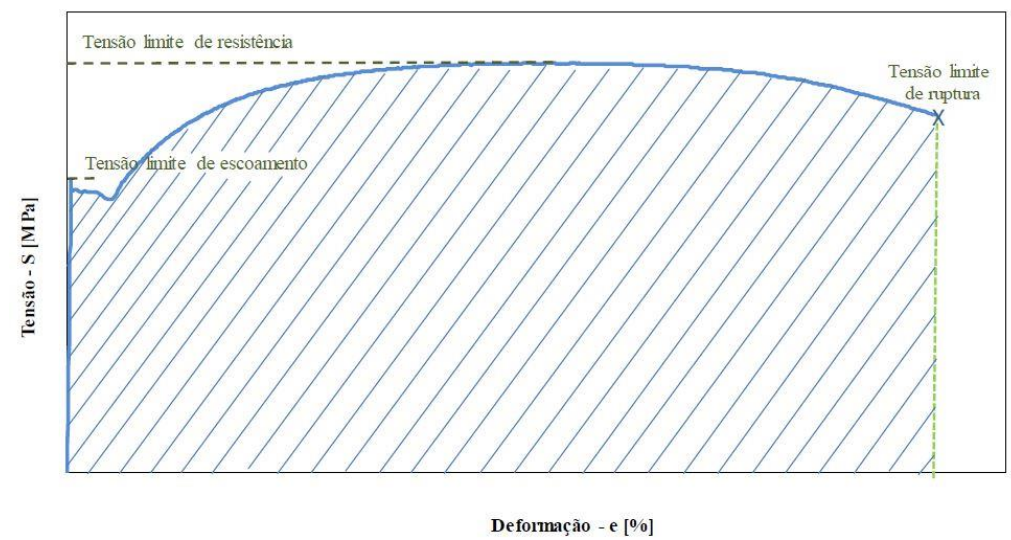

Figura 1. Curva tensão em função da deformação da área abaixo da curva, evidenciando o módulo de tenacidade do material ensaiado.

O ensaio de tração, entretanto, não mostra a resposta do material em condições de impactos abruptos, ou de elevadas taxas de deformação, já que há materiais cujas propriedades são diferentes, dependendo da taxa de deformação aplicada. Se uma carga muito menor for aplicada repentinamente, o que caracteriza uma solicitação dinâmica ou um teste dinâmico, o material pode falhar e aparentar ter menor resistência do que teria caso a mesma carga fosse aplicada de forma gradativa, Horath [3]. Sendo assim, considerando que o desempenho de alguns materiais é diretamente dependente da maneira como se aplica a carga, para situações de solicitações dinâmicas o ensaio de impacto é amplamente utilizado, particularmente quando há a necessidade de se estudar o comportamento dos materiais na transição do comportamento de fratura com micro mecanismo dúctil para frágil, como função da temperatura, Garcia, Spim e Santos [1]. Isso se dá também, pois, dentre suas vantagens, está o baixo custo e a relativa simplicidade na realização do mesmo, Silva [14].

Askeland e Phulé [15], também comentam que o ensaio de impacto é uma maneira rápida, conveniente e barata para comparar diferentes materiais, e justificam isso lembrando que nem sempre o valor de energia necessário para ruptura de um material, quando solicitado por tração, é o mesmo valor de energia requerido para ruptura de um material ensaiado por impacto. Além disso, citam que, em geral, é verdade que metais que apresentam alta resistência e alta ductilidade no ensaio de tração apresentam boa tenacidade, mas que isso deixa de ser verdade absoluta quando são consideradas altas taxas de deformação, como é o caso apresentado pelo ensaio de impacto. 
Basicamente, o ensaio consiste em promover a queda de um pêndulo de uma altura conhecida sobre a peça que se quer ensaiar. Um desenho esquemático do aparato experimental para ensaio de impacto encontra-se na Figura 2.

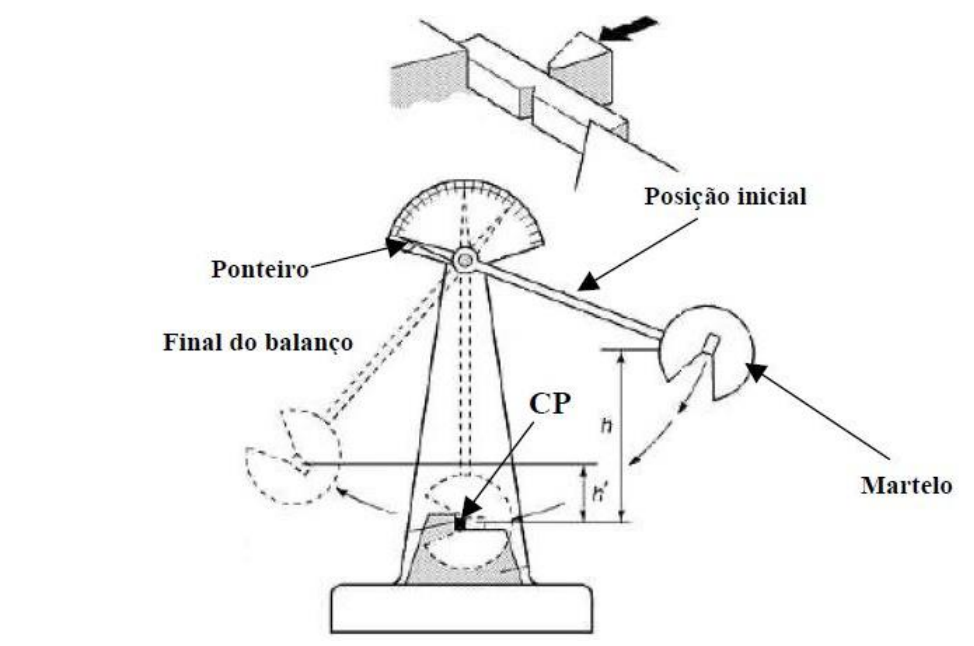

Figura 2. Desenho esquemático de uma máquina pendular de impacto Charpy.

O pêndulo é liberado de uma altura conhecida, posição inicial, e se choca com o corpo de prova. Após este choque, o pêndulo sobe novamente até uma altura menor que a inicial, posição final.

Garcia, Spim e Santos [1] comentam que apesar da praticidade e das vantagens do ensaio de impacto, é preciso atentar à padronização do corpo de prova, por motivos que serão esclarecidos a seguir, e às condições do ensaio, sendo elas um suporte rígido para apoio do corpo de prova, um pêndulo de massa conhecida e um dispositivo de escala para medir as alturas de soltura do pêndulo e sua altura posteriormente ao impacto com o corpo de prova. Esses requisitos são essenciais para garantir a reprodutibilidade do ensaio. Fazendo isso, quando se ensaiam diversos materiais sob as mesmas condições do ponto de vista da execução do ensaio, será possível então comparar as características desses materiais com a certeza de que não há outras interferências nos resultados obtidos. Horath [3] acrescenta que a fundação da máquina, as características do martelo e a velocidade de soltura também são itens que devem ser devidamente padronizados. O mesmo autor também diz que, no sistema de soltura da massa que atingirá o corpo de prova, não deve haver movimentação lateral do pêndulo, nem vibração que possa gerar perda de energia, e o martelo deve ser pesado o suficiente para que eventuais perdas de energia que ocorram no sistema, e que não sejam desprezíveis, e não sejam suficientes para invalidar o ensaio por não permitirem a quebra do corpo de prova.

Horath [3] diz que para entender o que ocorre no ensaio de impacto é necessário analisar o ensaio do ponto de vista da transferência, absorção e dissipação de energia. Isso se justifica, pois a diferença entre as alturas inicial e final do pêndulo, no qual pode ser relacionada à quantidade de energia absorvida pelo corpo de prova, conforme o princípio de conservação de energia. O mesmo autor comenta ainda que pode ocorrer deformação plástica dos elementos do sistema, e por consequência do efeito de histerese nas partes, fricção entre os elementos que interagem entre si e efeitos de inércia das partes móveis pode ocorrer perdas de energia ao sistema. 
Davim e Magalhães [16] representam o equilíbrio de energias citado anteriormente com a eq. (1), na forma:

$E_{m}=E_{c}+E_{p}+E_{\text {perdas }}$

onde $E_{m}$ é a energia mecânica envolvida no ensaio, $E_{c}$ é a energia cinética, $E_{p}$ é a energia potencial e $\mathrm{E}_{\text {perdas }}$ é a energia perdida por energia calorífica dissipada, energia elástica absorvida pela máquina, sendo esta última normalmente desprezível. Sendo assim, considerando que a energia mecânica do sistema será constante, ou seja, a energia mecânica inicial do sistema será a mesma que a sua energia mecânica final, matematicamente é o mesmo que escrever a eq. (2).

$E_{m \text { Inicial }}=E_{m \text { Final }}$

Utilizando a Figura 3 como referência, pode se utilizar o curso que o pêndulo realiza desde o momento da sua soltura, passando pelo impacto no corpo de prova até o ponto mais alto atingido antes de iniciar o movimento de retorno, que é a sua altura máxima final, para avaliar as condições de energia que ocorrem durante o ensaio.

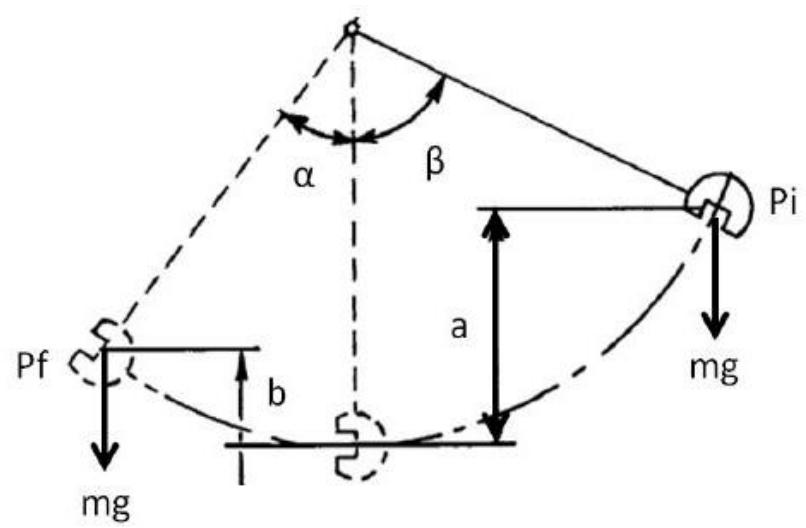

Figura 3. Representação esquemática do percurso que o pêndulo percorre durante o ensaio de impacto.

Considerando a posição inicial $\mathrm{P}_{\mathrm{i}}$ da Figura 3 , no momento exatamente anterior à soltura do pêndulo, tem-se que a $\mathrm{E}_{\mathrm{m}}$ do sistema quando o pêndulo encontra-se neste ponto equivale à máxima energia potencial e energia cinética nula, podendo portanto ser expressa pela eq. (3):

$E_{m \text { Inicial }}=m \cdot g \cdot a$

sendo $\mathrm{m}$ a massa utilizada no pêndulo em $\mathrm{kg}, \mathrm{g}$ a aceleração da gravidade em $\mathrm{m} \cdot \mathrm{s}^{-2} \mathrm{e}$ a altura da queda, em $\mathrm{m}$.

Já quando o pêndulo encontra-se no ponto final $\left(\mathrm{P}_{\mathrm{f}}\right), a \mathrm{E}_{\mathrm{m}}$ é a $\mathrm{E}_{\mathrm{p}}$ existente no pêndulo descontada a energia absorvida pelo corpo de prova no momento do impacto $\left(\mathrm{E}_{\mathrm{a}}\right)$, e desprezando as perdas do sistema, gera-se a eq. (4):

$E_{m \text { Final }}=m \cdot g \cdot a=m \cdot g \cdot a-E_{a}$

Substituindo a eq. (3) e a eq. (4) na eq. (2), obtém-se que a $E_{a}$ equivale à energia perdida pelo pêndulo no momento do impacto, que se revela pela sua perda de altura. 
Matematicamente, portanto, obtém-se a eq. (5):

$E_{a}=m \cdot g \cdot(a-b)$

sendo $(\mathrm{a}-\mathrm{b})$ a diferença de alturas que o pêndulo apresenta.

Quando se fala da utilização do ensaio de impacto Charpy para avaliação de tenacidade e determinação da TTDF de um material, fala-se da avaliação do modo de falha do material a diversas temperaturas, ou seja, deseja-se verificar se a falha ocorre de forma dúctil ou frágil a uma determinada temperatura. Lembrando que a fratura frágil é o modo mais crítico de falha, pois ocorre de maneira abrupta, objetiva-se utilizar o material a uma determinada condição onde isso não ocorra. Portanto, é necessário entender quando este tipo de fratura pode ocorrer para então poder evitá-la.

Garcia, Spim e Santos [1] citam que três são os fatores principais que contribuem para o surgimento da fratura frágil em materiais que normalmente são dúcteis à temperatura ambiente: a existência de um estado triaxial de tensões, baixas temperaturas e taxa de deformação elevada. A existência do entalhe no corpo de prova padronizado, a possibilidade de ensaiar materiais a diversas temperaturas e o maquinário que permite que a carga seja aplicada no material de maneira abrupta, fazem do ensaio Charpy um dos mais utilizados no estudo deste assunto.

O entalhe no corpo de prova gera um estado triaxial de tensões, por se tratar de um concentrador de tensões. Sem o entalhe, o corpo de prova deformaria plasticamente, e poderia não quebrar, o que invalidaria o ensaio, Horath [3]. Mostram-se na Figura 4 os três tipos diferentes de entalhe que podem ser utilizados no ensaio de impacto Charpy segundo a norma ASTM E23 [17], e na Figura 5 a forma com a qual esse corpo de prova é apoiado para que o pêndulo o atinja durante o ensaio. Cabe comentar que o corpo de prova tipo A é o mais utilizado, uma vez que o entalhe em "V" deste tipo de corpo de prova cria uma condição mais crítica de ensaio.

A concentração de tensões gerada pela utilização do entalhe em um corpo de prova confeccionado para realização de ensaio de impacto Charpy gera diferentes resultados quando se comparam diferentes estruturas cristalinas dos materiais. Callister [18] comenta que materiais de estrutura cúbica de face centrada (CFC), como a fase austenítica da matriz de aços inoxidáveis austeníticos, permanecem dúcteis mesmo em temperaturas extremamente baixas, porém os materiais de estrutura CCC, como a fase ferrítica dos mesmos aços, apresentam este tipo de transição. Garcia, Spim e Santos [1], por sua vez, apresenta o gráfico da Figura 6, comparando um aço inoxidável de estrutura CFC e um aço 0,6\% de carbono cuja estrutura cristalina é CCC, para evidenciar a diferença no comportamento do material quanto à transição dúctil-frágil, considerando o efeito da temperatura no comportamento do material. Meyers e Chawla [13] justificam esse efeito comentando que, com o aumento da temperatura, ocorre também um aumento na amplitude de vibração dos átomos do material, embora a frequência seja mantida, causando a dilatação térmica. Com isso, alteram-se o posicionamento atômico e as forças inter atômicas atuantes. Sabendo-se que a fratura ocorre pelo distanciamento dos átomos do material até um ponto crítico a partir do qual as forças de ligação atômicas não são suficientes para mantê-los ligados, se há alteração nesse equilíbrio de forças, haverá 
também alteração no comportamento do material quanto à sua ruptura.

Além do efeito da estrutura cristalina do material, há outras condições que impactam diretamente nos resultados obtidos no ensaio de impacto, os quais serão relatados a seguir.

- Efeito da geometria;

- Efeito da taxa de deformação;

- Posicionamento de retirada do corpo de prova e de confecção do entalhe.
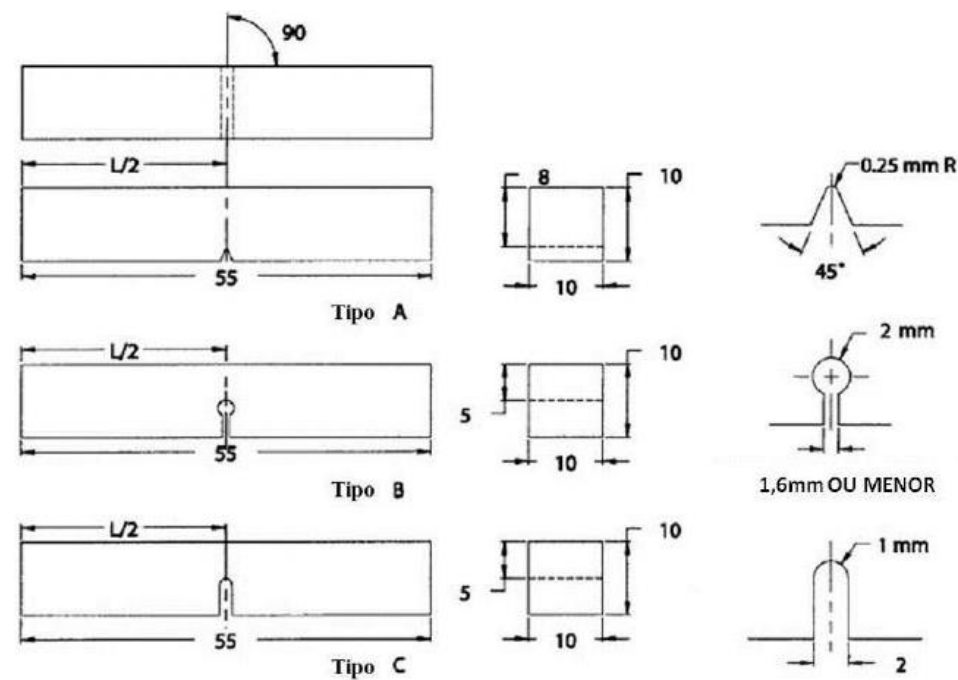

Figura 4. Formatos de corpo de prova para ensaio de impacto apresentados na norma ASTM E23.

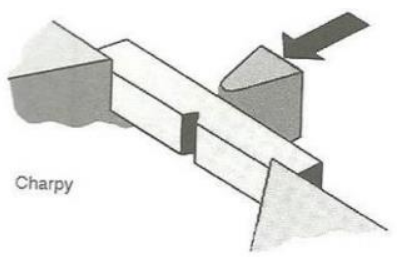

Figura 5. Posicionamento de um corpo de prova tipo A para ensaio de impacto Charpy.

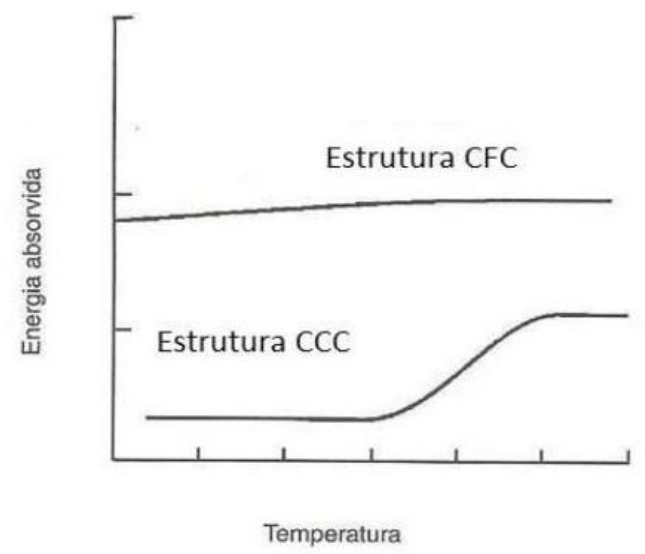

Figura 6. Curvas características de energia absorvida em função da temperatura para materiais com diferentes estruturas cristalinas.

1.2. Resultados Obtidos pelo Ensaio de Impacto 
Garcia, Spim e Santos [1] relacionam as informações que podem ser obtidas de um ensaio de impacto:

- Energia absorvida: obtida pela leitura da máquina;

- Contração ou expansão lateral: obtida pela medida das dimensões finais do corpo de prova na região da fratura, comparando-se com as medidas originais do mesmo;

- Aparência da fratura: determinação da porcentagem de fratura frágil ocorrida na fratura do corpo de prova, obtida pela avaliação da face de fratura do corpo de prova.

\subsection{Energia Absorvida em Função da Temperatura}

A partir do gráfico de energia absorvida em função da temperatura, é possível verificar a região de transição do comportamento de fratura do material de dúctil para frágil. O valor de energia absorvida é obtido pela leitura direta do valor na escala da máquina de ensaio de impacto. Sendo plotados esses valores em função da temperatura utilizada no ensaio, é possível verificar a mudança de comportamento do material de acordo com a mudança na temperatura de ensaio.

\subsubsection{Tratamento dos Dados pelo Método da Tangente Hiperbólica}

Para outros critérios de avaliação, a curva obtida deve ser ajustada, por exemplo, conforme o método descrito por Eircksonkirk e Shaikh [20].

De acordo com Gouveia [21], por este método, considerando-se os dados de energia absorvida em função da temperatura de ensaio, o ajuste feito por meio de formulação baseada em Tangente Hiperbólica é representado a partir da eq. (6).

$Y=A+B \cdot \tanh \left(\frac{T-D}{C}\right)$

sendo:

$\mathrm{A}=$ Média das energias entre patamares superior e inferior;

$\mathrm{B}=$ Amplitude entre energias dos patamares superior e inferior;

$\mathrm{C}=$ Metade da faixa da temperatura de transição;

$\mathrm{D}=$ Temperatura da média dos patamares inferior e superior;

$\mathrm{T}=$ Temperatura.

Primeiramente, se obtém os dados experimentais, executando o ensaio de impacto no material desejado, conforme mostrado na Figura 7.

Sendo EPI o valor de energia no patamar inferior e EPS o valor de energia no patamar superior, os valores de A e B podem então ser definidos, a partir dos dados experimentais e as definições acima citadas. A Figura 8 ilustra a determinação desses valores.

Em seguida, uma reta deve ser traçada com os dados da região de transição, de 
maneira que grande aderência seja obtida. Tem-se, então uma curva semelhante à Figura 9.

Com a equação obtida, determinam-se as temperaturas que representam as intersecções entre a região de transição e os patamares superior e inferior, igualando y às energias dos patamares superior e inferior.

Para definição de $\mathrm{C}$ e D, utiliza-se um algoritmo chamado Gradiente Reduzido Generalizado (GRG 2) para otimização de seus valores, de maneira a minimizar os erros quadrados, não-linearmente.

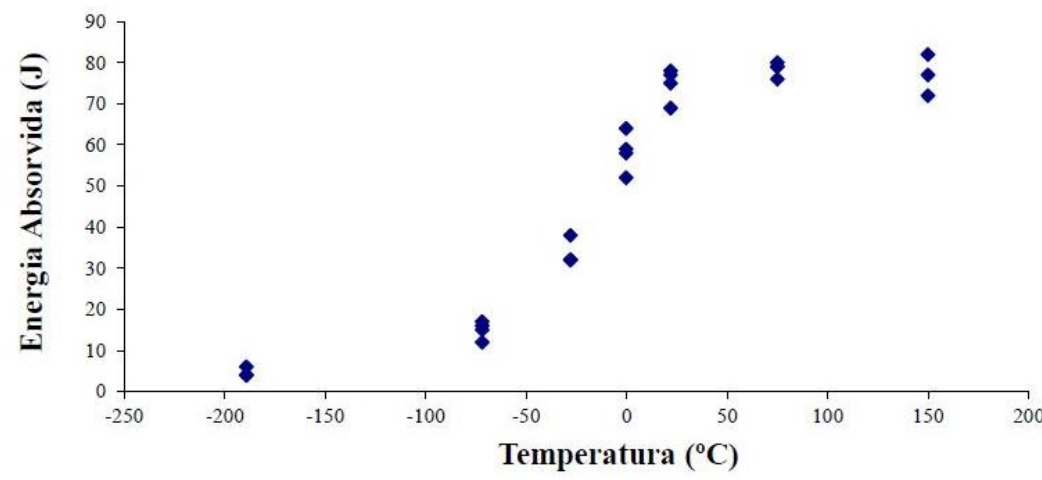

Figura 7. Dados experimentais de energia absorvida em função da temperatura.

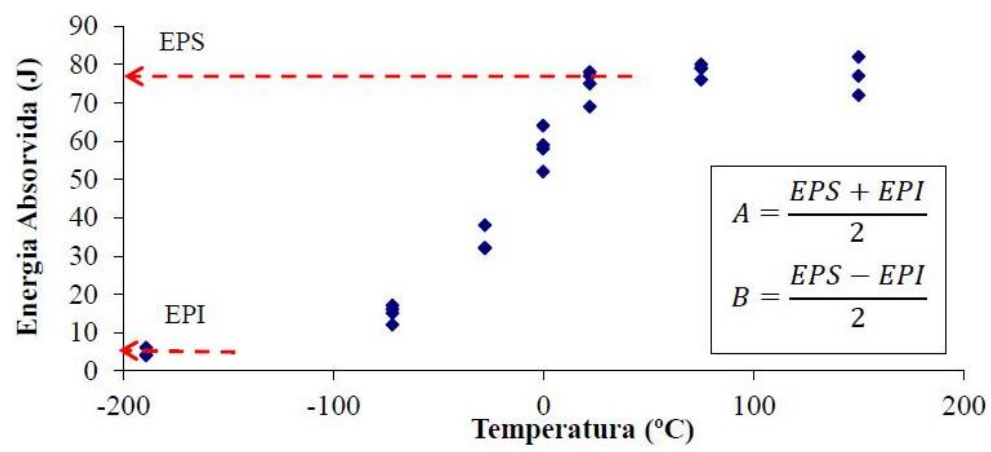

Figura 8. Ilustração da determinação dos parâmetros A e B a partir dos dados experimentais de energia absorvida em função da temperatura, para ajuste de curva pelo método da Tangente Hiperbólica.

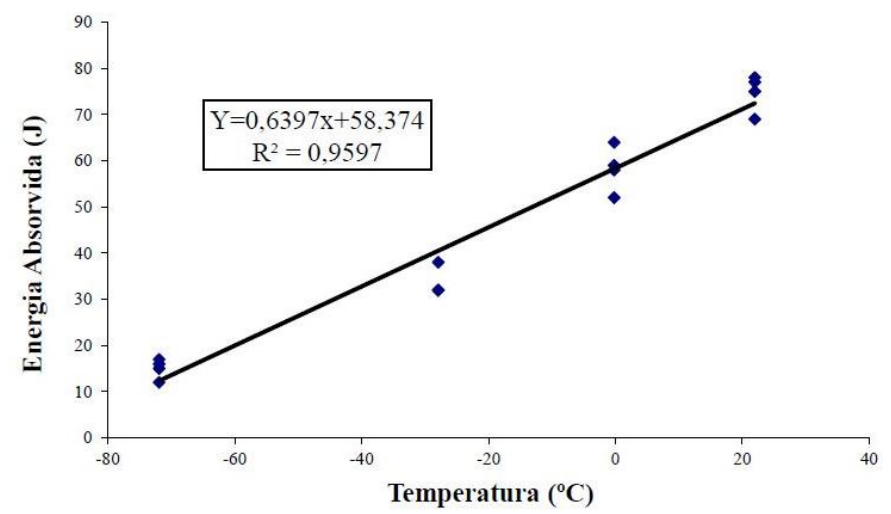

Figura 9. Gráfico de energia absorvida em função da temperatura da região de transição, para ajuste pelo método da Tangente Hiperbolica.

Com todos os valores definidos, pode-se gerar uma curva utilizando a eq. (6), com ajuste mais refinado, de maneira que a TTDF pode ser aquela na qual se tem a energia média entre os patamares superior (EPSaj) e inferior (EPIaj) 
ajustados pela nova curva. A curva final obtida por este ajuste, e os valores de EPSaj e EPIaj, são apresentados na Figura 10.

Cabe comentar que a metodologia de ajuste pelo método da Tangente Hiperbólica é exemplificada utilizando dados de energia absorvida em função da temperatura, mas poderiam ser utilizados os valores de porcentagem de fratura dúctil ou expansão lateral em função da temperatura.

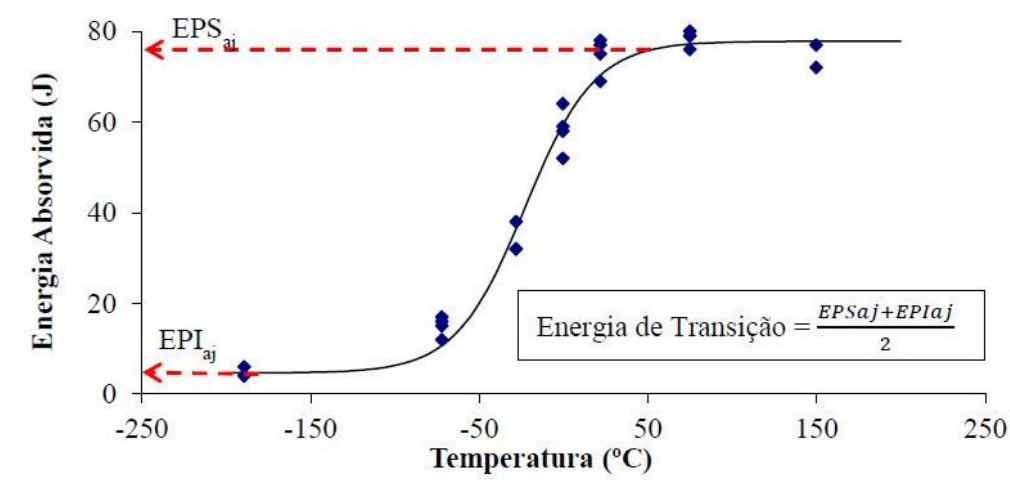

Figura 10. Dados de energia absorvida em função da temperatura ajustados pelo método da Tangente Hiperbólica, e indicação da determinação da TTDF a partir desta curva.

\subsection{Material Utilizado}

Realizou-se o ensaio de impacto Charpy para a medição da tenacidade, em corpos de prova de aço SAE 1020, com entalhe em V, orientado transversalmente à direção de laminação.

\subsection{Métodos}

O ensaio e a confecção dos corpos de prova foram especificados pela norma ASTM A 370 [12], sendo as dimensões dos corpos de prova de 10x10x55mm conforme mostrado na Figura 11. De acordo com a Figura 4, mostrado anteriormente, o corpo de prova utilizado no ensaio é do tipo A, no qual possui entalhe de $45^{\circ}$ e profundidade igual a $2 \mathrm{~mm}$.

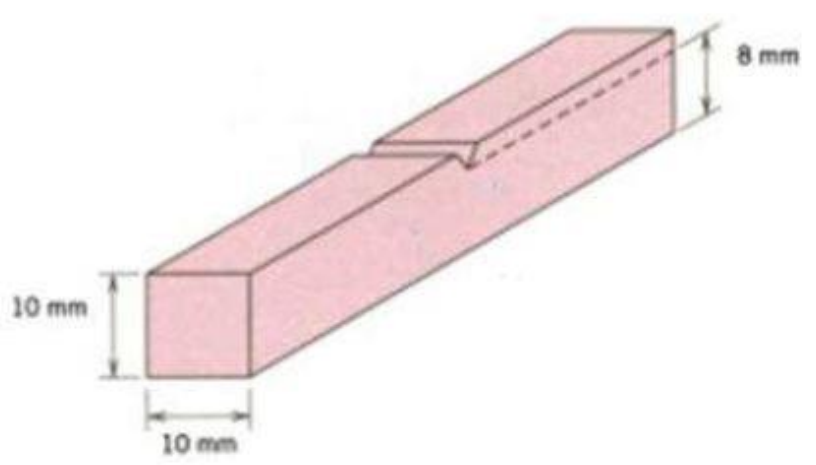

Figura 11. Corpo de prova para o ensaio de impacto Charpy.

Geralmente, o ensaio de impacto Charpy é medido em várias temperaturas, objetivando plotar o gráfico da transição dúctil-frágil. Dessa forma realizaram-se os ensaios sob seis temperaturas, sendo: $25,10,-10,-30,-50$ e $-70^{\circ} \mathrm{C}$. 
Os ensaios foram realizados a partir de um corpo de prova na temperatura ambiente, ou seja, $25^{\circ} \mathrm{C}$. Para que os corpos de prova atingissem temperaturas inferiores a ambiente, os mesmos foram mergulhados por $10 \mathrm{~min}$., para estabilização e homogeneização da temperatura no corpo de prova, em solução de álcool etílico e gelo seco, até que a temperatura estabilizasse, sendo que a leitura da temperatura foi realizada através de um termopar do tipo K imerso no banho.

Em seguida os corpos de prova foram imersos em nitrogênio líquido durante 5 min. antes do ensaio, com a intensão de resfriá-los. E no momento que a temperatura desejada foi atingida, a partir da medição com o termopar, retirou-se o corpo de prova com o auxílio de um alicate para imediatamente colocá-lo no pêndulo com carga inicial de 150J. Todo este procedimento foi realizado em menos de 5 segundos.

Neste estudo, a partir dos corpos de prova ensaiados ao impacto, obtiveram-se as seguintes informações em função da temperatura: energia absorvida e porcentagem de fratura frágil.

\subsection{Equipamentos e Meios Utilizados}

Os equipamentos no qual se executou os ensaios de tenacidade ao impacto pelo método Charpy com entalhe tipo $\mathrm{V}$, foram os seguintes:

- Máquina universal de ensaios de impacto marca Wolpert;

- Alicate;

- Paquímetro universal marca Mitutoyo;

- Termopar do tipo K.

A máquina universal de ensaios de impacto e o termopar utilizado são mostrados na Figura 12 e Figura 13, respectivamente.

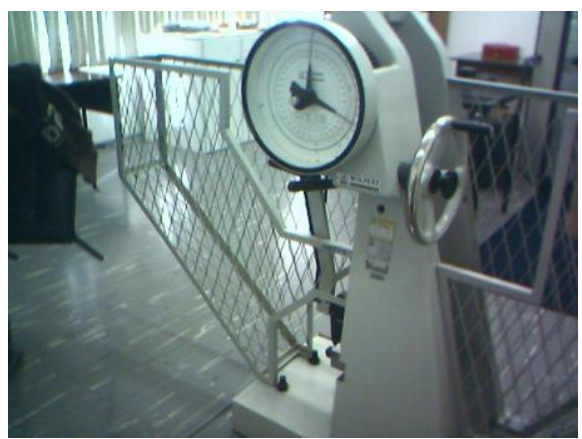

Figura 12. Máquina de ensaios de impacto marca Wolpert.

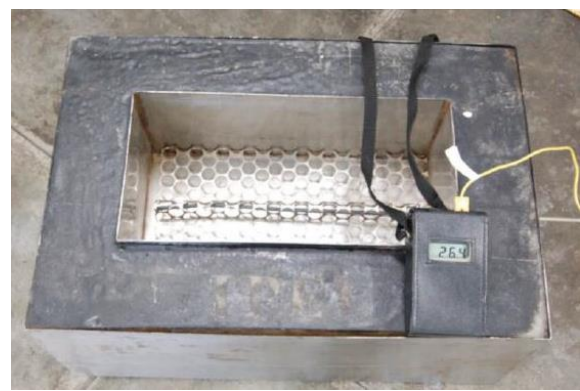

Figura 13. Registro do banho utilizado para imersão dos corpos de prova para atendimento às temperaturas desejadas para o ensaio dos materiais ao impacto e o posicionamento do termopar 
utilizado para conferência da temperatura.

\section{RESULTADOS E DISCUSSÃO}

Nesta seção são apresentados os resultados obtidos quanto à caracterização do material e após a realização dos ensaios. Também são apresentadas discussões sobre esses resultados, que levarão à posterior definição das conclusões deste trabalho.

São apresentados os resultados obtidos com a realização de ensaios de impacto Charpy, conforme norma ASTM A 370 [12], e a discussão dos mesmos.

Como resultado, os corpos de prova foram obtidos conforme solicitado pela norma ASTM A 370 [12]. O corpo de prova confeccionado é mostrado na Figura 14.

Realizado os ajustes necessários para a obtenção da temperatura desejada, fez-se o ensaio de impacto Charpy, no qual consiste na medição da tenacidade do material por meio de impacto. Neste ensaio, a posição do corpo de prova é horizontal, em que para efeito comparativo, no ensaio Izod, a posição do mesmo é vertical.

Através da Figura 15, é possível verificar o corpo de prova preparado para realizar o ensaio de impacto Charpy a partir da máquina universal de ensaios de impacto marca Wolpert. E na Figura 16, é mostrado o corpo de prova após o ensaio de impacto Charpy, no qual se verifica a sua ruptura decorrente do impacto durante a realização do ensaio.

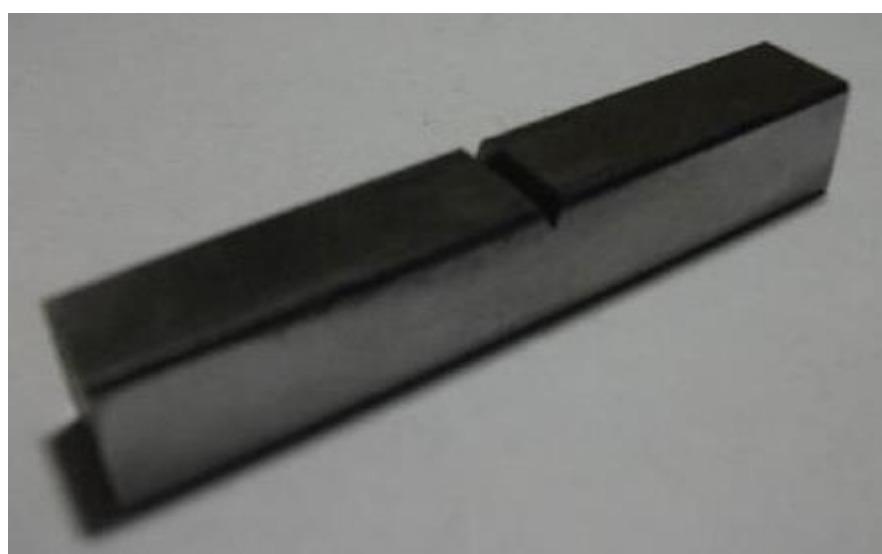

Figura 14. Corpo de prova confeccionado para realização deste trabalho.

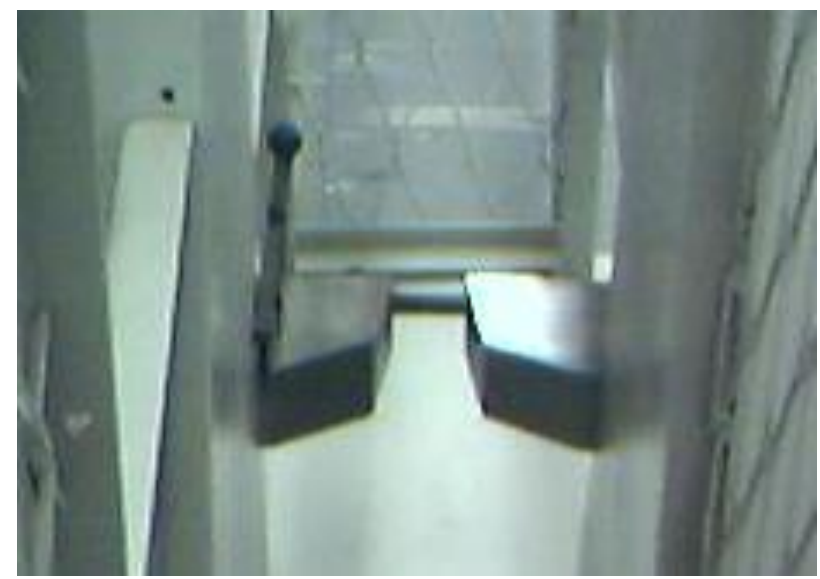

Figura 15. Corpo de prova localizado no equipamento para posterior ensaio. 


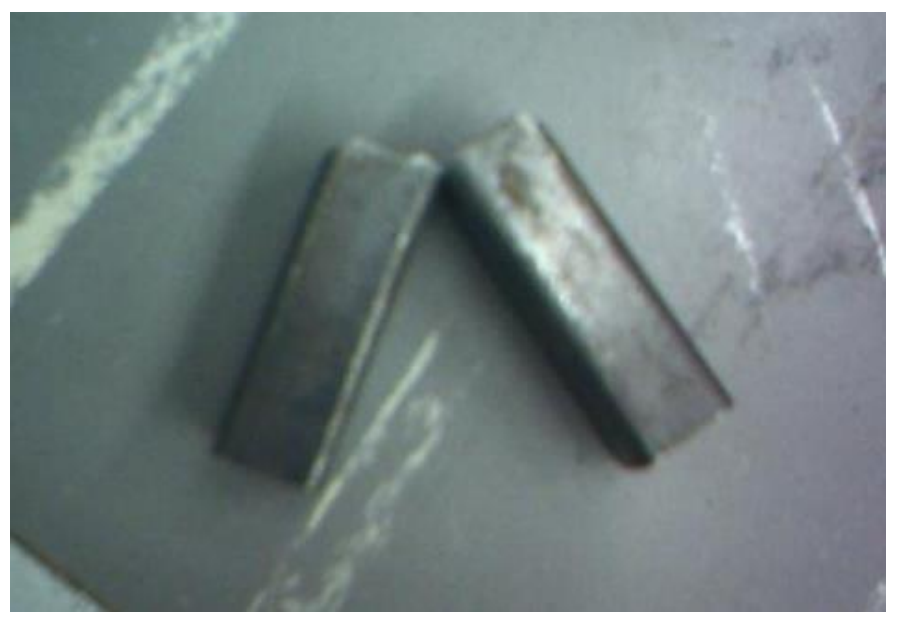

Figura 16. Corpo de prova após o ensaio.

Os resultados obtidos de energia absorvida em função da temperatura e índice de fragilidade para os corpos de prova nas 6 condições estão registradas na Tabela 1. Estes dados foram obtidos pela leitura direta dos valores de energia indicados na máquina de ensaio de impacto no momento da realização do ensaio, e foram colocados em um gráfico de energia absorvida em função da temperatura. Depois disso, esses dados foram tratados pelo método da Tangente Hiperbólica, e o gráfico obtido encontra-se na Figura 17, tornando possível verificar a diferença de comportamento na tenacidade do material.

A análise quantitativa da porcentagem de fratura frágil foi obtida através da medição da região de fratura plana, área brilhante, da face de fratura dos corpos de prova e posterior análise dos valores de acordo com a norma ASTM A 370 [12].

Pela sobreposição das curvas de ajuste obtidas para os dados de energia absorvida em função da temperatura do material nas 6 condições, fica mais fácil avaliar a diferença no comportamento do material.

Os resultados obtidos no decorrer dos ensaios foram registrados de acordo com a temperatura, já que o material dos corpos de prova ensaiados eram os mesmos. Todos os corpos de prova foram resfriados de acordo com as diferentes temperaturas, com exceção do corpo de prova ensaiado a temperatura ambiente, ou seja, $25^{\circ} \mathrm{C}$.

A partir dos resultados dos ensaios de impacto Charpy mostrados na Tabela 1 e Figura 17, pode-se avaliar o comportamento de tenacidade dos corpos de prova em relação à temperatura.

Tabela 1. Resultados de energia absorvida e índice de fragilidade em função da temperatura dos corpos de prova ensaiados ao impacto Charpy ajustado pelo método da Tangente Hiperbólica.

\begin{tabular}{|c|c|c|c|}
\hline Amostra & Temperatura $\left({ }^{\circ} \mathrm{C}\right)$ & Energia Absorvida $(\mathrm{J})$ & Índice de Fragilidade $(\%)$ \\
\hline 1 & 25 & 149 & 0 \\
\hline 2 & 10 & 114 & 50 \\
\hline 3 & -10 & 111 & 60 \\
\hline 4 & -30 & 59 & 85 \\
\hline 5 & -50 & 36 & 90 \\
\hline 6 & -70 & 3 & 98 \\
\hline
\end{tabular}




\section{Análise Do Ensaio De Charpy}

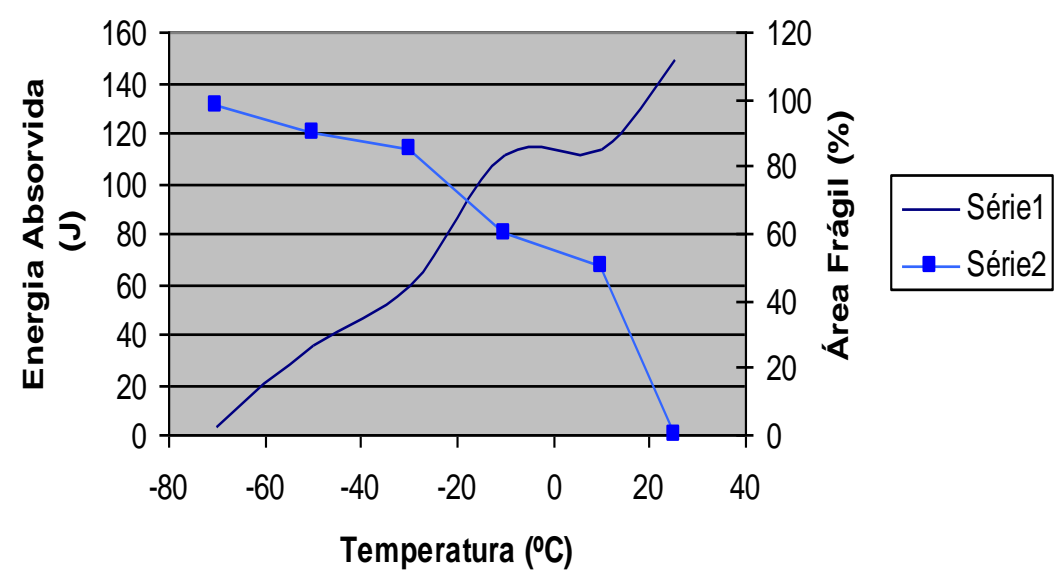

Figura 17. Gráfico de energia absorvida e índice de fragilidade em função da temperatura dos corpos de prova ensaiados ao impacto Charpy ajustado pelo método da Tangente Hiperbólica.

Iniciou-se os ensaios com a amostra 1, no qual o corpo de prova foi ensaiado na temperatura ambiente, ou seja, $25^{\circ} \mathrm{C}$. Nesse ensaio, a energia absorvida pelo corpo de prova foi de $149 \mathrm{~J}$, e o tamanho da seção transversal reduziu de 9,25 á 7,3mm, obtendo-se um índice de $0 \%$ de fragilidade.

Para a amostra 2, realizou-se o ensaio a temperatura de $10^{\circ} \mathrm{C}$. Nesse caso, a energia absorvida foi de $114 \mathrm{~J}$, e seção transversal reduziu de 9,35 á 7,65mm, obtendo-se dessa forma, um índice de fragilidade de $50 \%$.

A amostra 3 foi ensaiada a uma temperatura de $-10^{\circ} \mathrm{C}$, absorvendo uma energia de $111 \mathrm{~J}$, e a seção transversal reduziu de 9,35 á 7,85mm, obtendo-se um índice de fragilidade de $60 \%$.

A amostra 4 foi ensaiada a uma temperatura de $-30^{\circ} \mathrm{C}$, absorvendo uma energia de $59 \mathrm{~J}$, e a seção transversal reduziu de 9,35 á $8,4 \mathrm{~mm}$, obtendo-se um índice de fragilidade de $85 \%$.

Já a amostra 5, foi ensaiada a uma temperatura de $-50^{\circ} \mathrm{C}$, absorvendo uma energia de $36 \mathrm{~J}$, e a seção transversal reduziu de 9,35 á 8,9mm, obtendo-se um índice de fragilidade de $90 \%$.

Finalmente, a amostra 6 foi ensaiada a uma temperatura de $-70^{\circ} \mathrm{C}$, absorvendo uma energia de $3 \mathrm{~J}$, e a seção transversal reduziu de 9,35 á 9,3mm, obtendo-se um índice de fragilidade de $98 \%$.

Vê-se que, segundos os resultados obtidos, quanto maior a temperatura de ensaio, também é maior a energia absorvida e quanto menor a temperatura de ensaio, menor a energia absorvida, verificando dessa forma que a temperatura de ensaio influencia diretamente na tenacidade do material, obtendo-se, para o corpo de prova ensaiado, uma estrutura frágil em baixas temperaturas e uma estrutura mais dúctil em temperatura ambiente.

\section{CONCLUSÃO}

O desenvolvimento do estudo de ensaio de impacto Charpy em corpos de prova permitiu 
conhecer e entender esse tipo de ensaio, possibilitando fazer ensaios práticos em corpos de prova, além da aplicação dos conceitos teóricos estudados e especificações técnicas conforme norma para a confecção dos corpos de prova e realização dos ensaios, dessa forma permitindo verificar o comportamento do material do corpo de prova durante o ensaio prático.

A partir da metodologia utilizada no ensaio de impacto Charpy, conseguiu-se obter um melhor entendimento no que diz respeito a ensaios de impacto e análise do comportamento do material, conseguindo-se assim, verificar a energia absorvida em função da temperatura e índice de fragilidade para os corpos de prova ensaiados em diferentes temperaturas. A metodologia aplicada, também permitiu orientar e facilitar o desenvolvimento, possibilitando a realização do ensaio de forma adequada e segura, cumprindo os objetivos estabelecidos. Verificou-se com a realização dos ensaios, que é possível obterem propriedades mecânicas quanto à tenacidade de um material por meio de impacto.

Através desse desenvolvimento, percebeu-se que a temperatura influencia na tenacidade do material, obtendo-se, para o corpo de prova ensaiado, uma estrutura frágil em baixas temperaturas e uma estrutura mais dúctil em temperatura ambiente. Dessa maneira, pode-se determinar o correto material a ser empregado em diversas temperaturas.

Evidencia-se que quanto maior a temperatura de ensaio, também é maior a energia absorvida e quanto menor a temperatura de ensaio, menor a energia absorvida, verificando dessa forma que a temperatura de ensaio influencia diretamente na tenacidade do material. Verificou-se que para a temperatura de ensaio mais alta, ou seja, $25^{\circ} \mathrm{C}$, a energia absorvida pelo corpo de prova chegou a $149 \mathrm{~J}$, obtendo-se um índice de $0 \%$ de fragilidade, quanto que para a temperatura de ensaio mais baixa, ou seja, $-70^{\circ} \mathrm{C}$, a energia absorvida pelo corpo de prova foi de apenas 3J, obtendo-se um índice de fragilidade de $98 \%$.

\section{REFERÊNCIAS}

[1] GARCIA, A.; SPIM, J. A. e SANTOS, C. A.. Ensaio dos Materiais. LTC, Rio de Janeiro, 2008.

[2] HERTZBERG, R. W.. Deformation and Fracture Mechanics of Engineering Materials. Chichester: John Wiley, 4th ed., New York , 1996.

[3] HORATH, L.. Fundamentals of Materials Science for Technologists: Properties, Testing, and Laboratory Exercises. N. J: Prentice-Hall, Englewood Cliffs, 1995.

[4] SUMPTER, J. D. G. and KENT, J. S.. Fracture Toughness of Grade D Ship Steel. Engineering Fracture Mechanics, 28 p., 2006.

[5] IRELAND, D. R.. Critical Review of Instrumented impact Testing. Journal of Dynamic fracture Toughness, V.1, p. 47-62, 1977.

[6] BURDEKIN, F. M. and FOLCH, L. C. A.. Application of Coupled Brittle-Ductile Model to Study Correlation Between Charpy Energy and Fracture Toughness Values. Engineering Fracture Mechanics 63, p. 57-80, 1999.

[7] BENZERGA, A. A., DESANDRE, D., TVERGAARD, V., NEEDLEMAN, A.. Material Inertia and Size Effects in the Charpy V-Notch Test. European Journal of Mechanics A/Solids 23, p. 373-386, 2004.

[8] SOUZA, S. A. de. Ensaios Mecânicos de Materiais Metálicos. Edgard Blucher, 5.ed., São Paulo, 1982.

[9] KOBAYASHI, T., KIM, H. J. and MORITA, S.. Progress and Development in the Instrumented Charpy Impact Test, Mat. - Wiss. U. Werkstofftech 32, p. 525-531, 2001.

[10] SRIVATSAN, T. S., LAM, P. C. and KRAUSE, J.. The Impact Toughness 
Characteristics of Steel Wire-Reinforced polymer Composites. Materials Letters, p. 324-328, 2009.

[11] ZAPPINI, G., KAMMANN, A. and WACHTER, W.. Comparison of Fracture Tests of Denture Base Materials. The Journal of Prosthetic Dentistry, p. 578-585, 2003.

[12] ASTM A 370 - 06. Standard Test Methods and Definitions for Mechanical Testing of Steel Products, November, 2006.

[13] MEYERS, M. A. and CHAWLA, K. K.. Mechanical Behavior of Materials. Prentice-Hall, New Jersey, 1999.

[14] SILVA, R. V.. Avaliação da Tenacidade à Fratura de Soldas de Alta Resistência e Baixa Liga pelo Método da Integral J. Dissertação, São Carlos, 1998.

[15] ASKELAND, D. R. and PHULÉ, P. P.. The Science and Engineering of Materials. Thomson Learning, 5th ed., Austrália, 2006.

[16] DAVIM, J. P. e MAGALHÃES, A. G.. Ensaios Mecânicos e Tecnológicos: Inclui Exercícios Resolvidos e Propostos. Publindústria, 2. ed., Porto, Portugal, 2004.

[17] ASTM E23 - American Society for Testing and Materials. Standard Test Methods for Notched Bar Impact Testing of Metallic Materials. Philadelfia, USA, 2012.

[18] CALLISTER, W. D.. Fundamentals of Materials Science and Engineering: An Introduction. John Wiley, 2nd. ed., New Jersey, 2005.

[19] GOST 9454 - Standards Publishing House. Impact Bending Test Method at Low, Room and High Temperatures. Moscow, 1978.

[20] EIRCKSONKIRK, M. and SHAIKH, A.. Insights and Observations Arising from curve-fitting the Charpy V-Notch and Tensile data Contained within the United Stats' Light Water Reactor Surveillance Database. In: Proceedings of PVP2008-61650, ASME, 2008.

[21] GOUVEIA, K. C.. Investigação dos Métodos de Determinação da Temperatura de Transição Dúctil-Frágia (TTDF) Utilizando Ensaio de Impacto Charpy. Dissertação de Mestrado em Engenharia Mecânica, Centro Universitário da FEI, São Bernardo do Campo, 2013. 